\title{
Angioedema of the small bowel caused by lisinopril
}

\author{
Mark Terence P Mujer, ${ }^{1}$ Manoj P Rai, ${ }^{1}$ Divyesh Reddy Nemakayala, ${ }^{1}$ Julie L Yam²
}

'Department of Internal Medicine, Michigan State University, Lansing, Michigan, USA

${ }^{2}$ Gastroenterology, McLaren of Greater Lansing, Lansing, Michigan, United States of America

\section{Correspondence to Dr Manoj P Rai, manoj.rai@hc.msu.edu}

MTPM and MPR contributed equally.

Accepted 19 April 2018

\section{DESCRIPTION}

A 42-year-old man with a history of chronic kidney disease (stage III) and hypertension presented to an outside hospital with acute onset of left lower quadrant abdominal pain that woke him from his sleep. He described the pain as $8 / 10$ in severity, cramping in nature and worsened by eating or drinking. Pain was associated with nausea, intractable vomiting, dyspnoea and dizziness. Ten-point review of systems was negative except for the above reported symptoms.

Vitals on admission were stable. He had tenderness over the suprapubic and left lower quadrant. Physical exam was otherwise unremarkable. His white cell count was elevated at $14.6 \times 10^{3}$ per microlitre, haemoglobin was $17.0 \mathrm{~g} / \mathrm{dL}$, lactate was $1.9 \mathrm{mg} / \mathrm{dL}$ and lipase and stool studies were negative. Initial CT of the abdomen pelvis (figure 1) with contrast showed thick-walled small bowel loops of the proximal ileum and jejunum with surrounding haziness producing luminal narrowing. There was also evidence of mild free fluid in abdominal and pelvic cavities. At this time, possible inflammatory bowel disease or colitis was suspected, and he was started on empirical ciprofloxacin and metronidazole. He was kept on bowel rest. However, there was minimal improvement of his symptoms. $\mathrm{He}$ was subsequently transferred to our hospital after 3 days for further evaluation by the gastroenterology (GI) service.

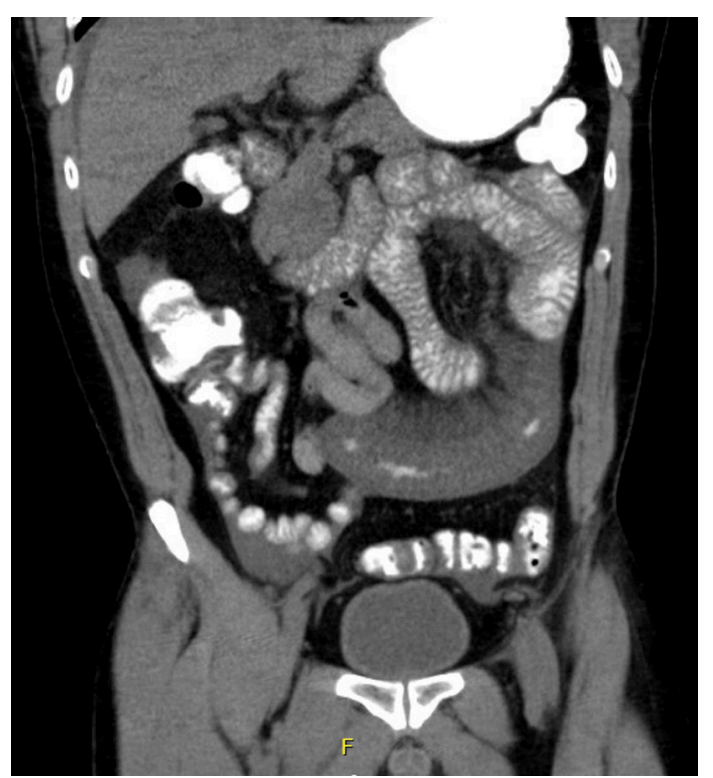

To cite: Mujer MTP, Rai MP, Nemakayala DR, et al. BMJ Case Rep Published Online First: [please include Day Month Year]. doi:10.1136/ bcr-2018-225396
Figure $1 \mathrm{CT}$ of the abdomen pelvis with contrast showing thick-walled small bowel loops of the proximal ileum and jejunum with surrounding haziness producing luminal narrowing. There was also evidence of mild free fluid in abdominal and pelvic cavities.

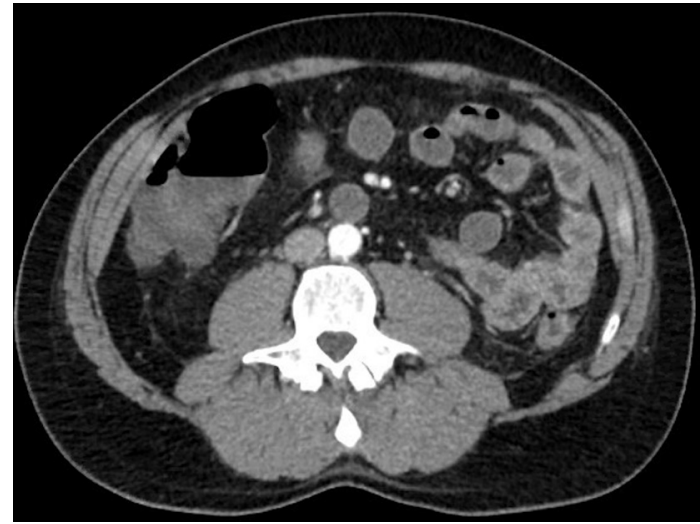

Figure 2 CT enterography (axial section) showing diffuse thickening of the wall and fluid surrounding the distal small bowel; proximal ileum involvement was greater than jejunum.

A CT enterography (CTE) (figures 2 and 3) was then obtained that showed diffuse thickening of the wall and fluid surrounding the distal small bowel; proximal ileum involvement was greater than jejunum. There was moderate volume of free intra-abdominal fluid as well. A careful review of his history revealed that the patient was recently started on lisinopril approximately 2 weeks prior to the onset of symptoms. ACE inhibitors (ACEi) have been known to cause angioedema, and there are few case reports on angioedema of the small bowel due to ACEi. Lisinopril was immediately discontinued. Patient had improvement of his symptoms in 24 hours and was subsequently discharged with no further recurrence.

Various differentials such as infectious colitis, inflammatory colitis, medication induced colitis, ischaemic colitis and hereditary angioedema were considered. Even though there was mild elevation of white cell count, other infectious work up including blood cultures and stool studies were negative, and there was no improvement with antibiotic treatment; thus, possible infectious cause was ruled out. Inflammatory colitis was ruled out since the patient did not have any GI symptoms prior to this admission, there was no evidence of GI bleed and the CTE was negative for findings of ulcerative colitis or Crohn's disease. The abdominal pain was not characteristic for ischaemic colitis, there was no evidence of GI bleed and the patient did not have any risk factors for the development of ischemia. There was no personal or family history of previous angioedema, so hereditary angioedema was thought to be unlikely in this case. The patient was not on medications (NSAIDS, ipilimumab, mycophenolate, gold and retinoic acid) known to cause medication-associated colitis. Lisinopril was then thought 


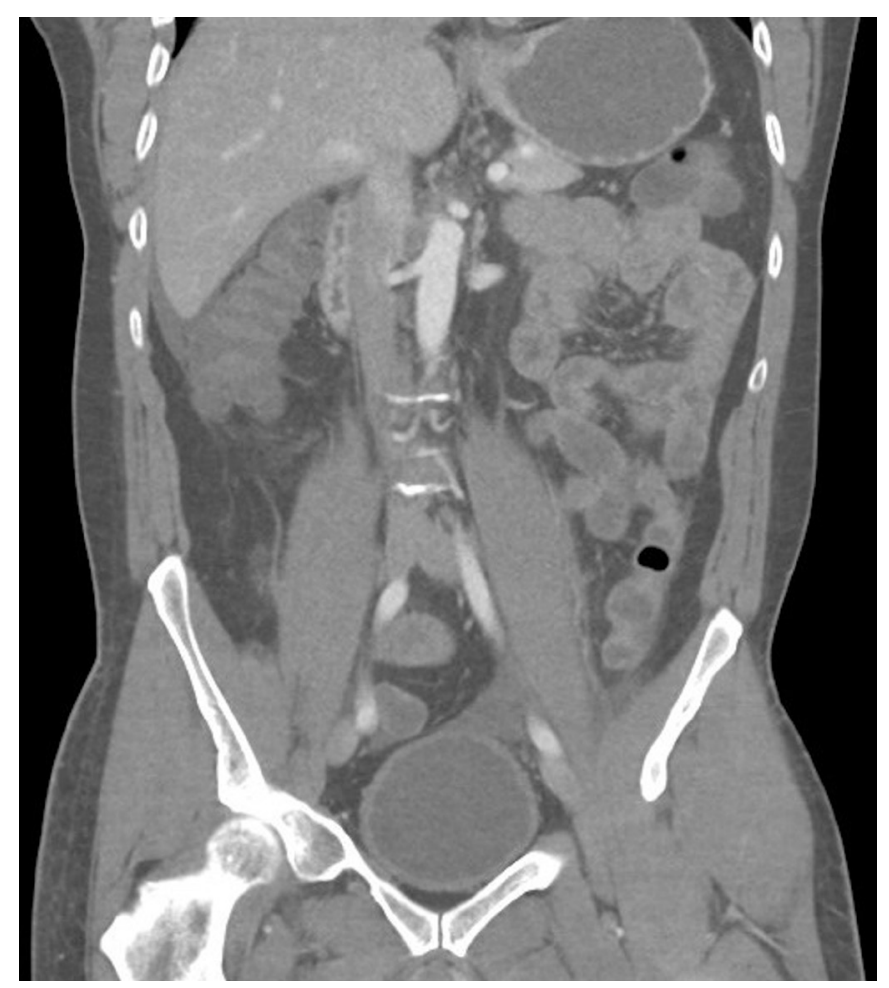

Figure 3 CT enterography (coronal section) showing diffuse thickening of the wall and fluid surrounding the distal small bowel; proximal ileum involvement was greater than jejunum.

to be the cause given the temporal relationship between starting lisinopril and the onset of the small bowel angioedema, the radiological findings and the rapid resolution of symptoms on discontinuation of the drug.

ACEi-induced angioedema of the small intestine is a rare adverse reaction ${ }^{1}$; yet, it is important to recognise this side effect as the drug is one of the most commonly prescribed medications in the country. As the symptoms of visceral angioedema may mimic other diseases, it may lead to misdiagnosis or unnecessary work up and procedures. Onset of symptoms is usually within days to weeks of initiation of the drug. ${ }^{2}$ Patients commonly present with abdominal pain, nausea, vomiting and diarrhoea, and it occurs more frequently in females than males. ${ }^{1}$ CT of the abdomen is known to show segmental oedema of the small bowel, mild dilatation, straightening and ascites among patients with angioedema. ${ }^{3}$ Symptoms classically subside within 24-48 hours after discontinuation of the ACEi. Thus, it is an important diagnosis to consider in patients with acute onset of abdominal pain on ACEi therapy.

\section{Learning points}

- ACE inhibitors (ACEi)-induced angioedema can involve any visceral organ, but most common sites include the tongue, oropharynx and the periorbital/perioral regions.

- Patients typically present with abdominal pain, nausea, vomiting and diarrhoea within days to weeks of initiation of the ACEi. Patients generally improve within 24-48 hours after cessation of the medication.

Contributors All authors contributed equally to the manuscript.

Funding The authors have not declared a specific grant for this research from any funding agency in the public, commercial or not-for-profit sectors.

Competing interests None declared.

Patient consent Obtained.

Provenance and peer review Not commissioned; externally peer reviewed.

(c) BMJ Publishing Group Ltd (unless otherwise stated in the text of the article) 2018. All rights reserved. No commercial use is permitted unless otherwise expressly granted.

\section{REFERENCES}

1 Palmquist $\mathrm{S}$, Mathews B. Isolated intestinal type angioedema due to ACE-inhibitor therapy. Clin Case Rep 2017;5:707-10.

2 Lin RY, Shah SN. Increasing hospitalizations due to angioedema in the United States. Ann Allergy Asthma Immunol 2008;101:185-92.

3 Scheirey CD, Scholz FJ, Shortsleeve MJ, et al. Angiotensin-converting enzyme inhibitorinduced small-bowel angioedema: clinical and imaging findings in 20 patients. AJR Am J Roentgenol 2011;197:393-8.

Copyright 2018 BMJ Publishing Group. All rights reserved. For permission to reuse any of this content visit

http://group.bmj.com/group/rights-licensing/permissions.

BMJ Case Report Fellows may re-use this article for personal use and teaching without any further permission.

Become a Fellow of BMJ Case Reports today and you can:

- Submit as many cases as you like

- Enjoy fast sympathetic peer review and rapid publication of accepted articles

- Access all the published articles

- Re-use any of the published material for personal use and teaching without further permission

For information on Institutional Fellowships contact consortiasales@bmjgroup.com

Visit casereports.bmj.com for more articles like this and to become a Fellow 